\title{
Pregnant women's fear of childbirth in midwife- and obstetrician-led care in Belgium and the Netherlands: test of the medicalization hypothesis
}

\begin{abstract}
Fear of childbirth has gained importance in the context of increasing medicalization of childbirth. Belgian and the Dutch societies are very similar but differ with regard to the organization of maternity care. The Dutch have a high percentage of home births and low medical intervention rates. In contrast, home births in Belgium are rarer, and the medical model is more widely used. By comparing the Belgian and the Dutch maternity care models we explored the association between fear of childbirth and medicalization.

An antenatal questionnaire was completed by 833 women at 30 weeks of pregnancy.

Fear of childbirth was measured by a shortened Dutch version of the Childbirth Attitudes Questionnaire. A four-dimensional model with baby-related, pain and injuries-related, general and personal control-related, and medical interventions and hospital care-related fear, fitted well in both countries. Multiple regression analysis showed no country differences, except that Belgian women in midwife-led care were more fearful of medical interventions and hospital care than the Dutch. For the other dimensions, both Belgian and Dutch women receiving midwifery care reported less fear compared to those in obstetric antenatal care. Hence, irrespective of the maternity care model, antenatal care providers are crucial in preventing fear of childbirth.
\end{abstract}




\section{INTRODUCTION}

During pregnancy, women anticipate the event of childbirth. Pregnant women develop expectations and worries regarding labor and delivery that are influenced by the mothers' personal experiences and experiences of significant others, by their antenatal care providers, and by cultural background (Fenwick, Hauck, Downie, \& Butt, 2005). Although women in Western, industrialized countries face minimal risks of adverse outcomes, research has shown a high prevalence of fear associated with childbirth (Zar, Wijma, \& Wijma, 2001). Up to $80 \%$ of women identify frequent worries (Saisto \& Halmesmaki, 2003), 17-20\% report moderate fear (Kjaerggard, Wijma, Dykes, \& Alehagen, 2008), and 6-10\% of women experience severe, disabling fear of labor and delivery (Wijma, 2003; Areskog, Uddenberg, \& Kjessler, 1981).

Rising obstetric interventions, especially caesarean sections, may be related to women's fear of childbirth (Saisto \& Halmesmaki, 2007; Sjogren, 2000). In Western countries, childbirth is increasingly managed as a medical problem: women no longer give birth, but are delivered; fetuses are monitored and screened; labor can be artificially induced or stopped, and effective pain relief is widely used. Women's expectations might reflect this process of increasing medicalization of childbirth (Johanson, Newburn, \& Macfarlane, 2002). How, then, is the occurrence of fear of childbirth explained in contexts in which medical assistance is readily available? Are women fearful because medicine is too little or too readily available? The challenge is to find out under what conditions fear of childbirth occurs. 
This study had two aims. The first was to propose and test a clear conceptual model of fear of childbirth. The second was to explore the association between fear of childbirth and medicalization by comparing two maternity care models - the Belgian and the Dutch.

\section{Fear of Childbirth}

Childbirth may be a specific object of fear during pregnancy. Previous research has identified fear of childbirth as an important dimension of pregnancy anxiety. Using a shortened version of the Childbirth Attitudes Scale (Lowe, 2000) we tested an underlying factor structure based on: 1) the results of an exploratory factor analysis and 2) a literature review. Several authors have hypothesized theoretical dimensions of fear, but few have tested them by means of factor analysis. One exception was the study of Johnson and Slade (2002) who identified four factors within the Wijma Delivery Expectancy Scale (W-DEQ) by means of principal components analysis. The scale reflects fear of childbirth, the positive aspects of bearing a child, the risks inherent in labour and feelings of isolation. On theoretical grounds Saisto and Halmesmäki (2003) argued that the nature of fear of childbirth may be biological (e.g., fear of pain), psychological (e.g., related to personality), social (lack of support), or secondary (e.g., originating from previous experiences). However, these categories are not mutually exclusive and do not mention the well-being of the baby, although this is the focus of most childbirth concerns (Searle, 1996). In the current study, we used the first three categories: biological, because fear of labor pain is a frequent reason for fear of childbirth (Saisto et al., 2003), and psychological and social, because these have also been confirmed by the Wijma et al. (2002) study. The latter study made a distinction between personal and external conditions that generate fear. Personal conditions reflect worries about maintaining personal control, while external conditions relate to the context or environment in which women give birth. In sum, we proposed four dimensions of fear of childbirth: 1) fear about the baby's well-being, 2) fear of labor pain and injuries, 3) personal control related fear, and 4) fear of medical interventions and hospital care. 


\section{Fear of Childbirth in two maternity care models}

Fear of childbirth is a personal, emotional experience constructed in interaction with the social environment (Eriksson, Westman, \& Hamberg, 2005) and shaped by the maternity care system and the antenatal care provider (Fisher, Hauck, \& Fenwick, 2006). Because Belgium and the Netherlands have different models of maternity care, we expected to uncover different experiences with fear of childbirth in both countries.

In Belgium, mainstream birth practices are obstetric with a bio-medical focus, which corresponds to the medical model as described by, for example, Davis-Floyd (2001) and van Teijlingen (2005). Belgian maternity care is organized around the concept of risk instead of normality. More than $98 \%$ of all women in Belgium deliver in hospital. The majority of Belgian women consider the hospital the only safe place for childbirth (Gilleir, 2007). In Belgium, more than $98 \%$ of all women get antenatal care from the obstetrician who also supervises the subsequent delivery. Hence pregnant women have continuity of specialist care throughout pregnancy and childbirth, unless women choose otherwise or the obstetrician is unavailable (e.g., vacation) at the time of birth. A minority of women, those who want to give birth at home, see a team of midwives during pregnancy, and a member of that team accompanies them during birth.

In contrast, Dutch birth practices are predominantly midwife-led and women-centered, corresponding to the midwifery as opposed to the medical model. The Netherlands has a high percentage of home births, low intervention rates, and specific ideology of childbirth (Van der Hulst et al., 2007). Childbirth is believed to be a normal physiological process (Johnson, Callister, Freeborn, Beckstrand, \& Huender, 2007), requiring little intervention. In maternity care, this belief is expressed by emphasizing primary care. Because a gate-keeping model of access to (specialty) care is used, pregnant women are encouraged to use the services of primary health care providers, such as midwives and general practitioners. This results in a $21.5 \%$ home birth rate, $11.3 \%$ polyclinical births (taken together, this is $32.8 \%$ in primary care), and low intervention rates (Stichting Perinatale Registratie Nederland (SPRN), 2007). When problems, as defined by the Verloskundige indicatielijst 
(list of obstetric indications), are encountered during pregnancy or labor, women are referred to specialist care (Wiegers, van der Zee, \& Keirse, 1998). Women are unsure which team member will provide care at each antenatal consult and at the moment of birth but have usually met each of them at least once before delivery. Referrals from home to hospital during pregnancy or labor likewise often reduce the continuity of care (Christiaens, Gouwy, \& Bracke, 2007).

In accordance with medicalization critics, such as Illich (1976), who emphasized the iatrogenic effect of medicalization, or Zola (1972), who theorized about its social control function, the bio-medical approach might induce fear. By constructing childbirth as an uncontrollable and unpredictable process, risks are emphasized, and fear that something could go wrong may thus be cultivated. However, medicalization has also a reassuring effect. According to Western society's fundamental beliefs about the superiority of technology over nature (Davis-Floyd, 1994), medical technology makes childbirth relatively predictable and controllable. The question becomes how these contradictory effects of medicalization, fear induction and reassurance, translate into the emotional experiences of childbearing women.

Therefore, in accordance with medicalization critics, and because antenatal care providers play an important role in the expectations women develop during pregnancy (Hildingsson, Waldenstrom, \& Radestad, 2002), we expected to find that more women feared childbirth in contexts in which the technocratic model of childbirth prevails. Hence, we expected to find that this was more the case for Belgian than for Dutch women and among women with secondary compared to primary antenatal care providers within each country. If medicalization had a reassuring effect, however, the opposite finding was hypothesized: Belgian women and women in secondary care would then be less fearful of childbirth compared to Dutch women and women in primary care.

\section{METHODS}


Study Population. Belgian and Dutch women were invited to participate in the study through five hospitals and 27 midwifery practices in two cities, one in Belgium and one in the Netherlands, Ghent and Tilburg, respectively, with comparable socio-demographics (e.g., number of births in 2004: Ghent, 2,931; Tilburg, 2,400; number of women aged 15-44 years in 2005: Ghent, 48,139; Tilburg, 45,227; population density: Ghent, 1,478; Tilburg, 1,675). Although we should be careful of generalizing the results to all of Belgium and the Netherlands, and although the Belgian part of the study was limited to the Flemish region (the northern, Dutch-speaking part of Belgium), we will refer to Belgium and the Netherlands, and to the Belgian and the Dutch, to enhance the readability of the paper.

We approached all hospitals in both cities. Because the population of pregnant women was unknown, we had to rely on a convenience sample. Ghent had four hospitals, three of which agreed to participate. We have no reason to believe that the population of the non-participating hospital differed from the population of the participating hospitals. In Tilburg, both hospitals agreed to cooperate. Because more births occur in hospital than at home in both countries, we needed to over-sample the home deliveries. Assuming a confidence interval of $0,95 \%$ we calculated a minimum sample size of 600 respondents (see Cochran 1977). Taking into account a non-response of 50\%, we strived for a minimum of 1200 eligible respondents, or 300 in each birth setting in each country (Belgium versus the Netherlands) and place of birth (home versus hospital). As many midwifery practices as necessary were contacted to reach a number of 300 eligible women in each country. In Tilburg (NL) this was already achieved with 6 midwifery practices. In Flanders with only about 650 home deliveries each year (SPE, 2005), we went beyond the city borders of Ghent and contacted 21 midwifery practices spread out across Flanders.

To include both home and hospital births, all women were asked by their midwife or obstetrician to participate in the research project during antenatal visits. Inclusion criteria were broad: both Belgian and Dutch women had to speak and understand Dutch and had to be 18 years or older. The questionnaire was handed out during a visit at 30 weeks of pregnancy together with an 
information sheet. It was returned to the obstetrician or midwife during one of the following antenatal visits.

A written informed consent was requested of all respondents, and was completed at the same time that the first questionnaire was filled in. Anonymity was ensured as no personally identifiable data were collected. The Committee for Ethics of the University Hospital has approved the study.

At 30 weeks of pregnancy, 833 women (or $45 \%$ of all eligible women ( $N=1832$ )) filled out the questionnaire. The analyses were run on the sample of 833 women, which was reduced to 790 due to missing data for parity $(n=12)$, age $(n=10)$, or education $(n=21)$.

Because women were recruited during antenatal visits to their obstetricians and midwives, we had little control over the inclusion process and, consequentially, the response rate. Although we asked that women who refused to participate be registered, this was not systematically done by every hospital. As a result, we do not know the exact number of women invited to participate in this study. To calculate the response rate we used the number of questionnaires provided to physicians and midwives; the number of eligible women was based on an estimate made by midwives and obstetricians acting as proxy. The response rate was calculated by dividing the number of respondents by the number of questionnaires provided to practitioners. This calculation resulted in an average response rate of $43 \%(n=238)$ for all Belgian hospitals, $41 \%(n=137)$ for Belgian midwifery practices, $42 \%(n=208)$ for Dutch hospitals and $54 \%(n=244)$ for Dutch midwifery practices. For hospitals, the smallest response rate was $19 \%$, the highest $68 \%$. For the midwifery practices, the range of response rates was $38 \%$ to $100 \%$. However, we know that not all questionnaires were distributed, which means that our estimations of the response rates are in fact very conservative.

Data collection. To contact as many women as possible in a short period, a survey was conducted. Respondents filled in an antenatal questionnaire at 30 weeks of pregnancy. This timeframe was chosen because at that point in pregnancy the focus of women's anxiety shifts away from the pregnancy and toward the experience of labor (Watson, Elliot, Rugg, et al., 1984). Women were 
invited to participate during a span of approximately three months. Because the data collection was not simultaneously organized in each hospital/midwifery practice, one year-from September 2004 to September 2005-was necessary to gather the data.

Measures. Fear of childbirth was measured by a shortened Dutch version of the Childbirth Attitudes Questionnaire developed by Lowe (2000). Three items were omitted from the original 16item instrument. During the pilot study, the questionnaire was reviewed by care providers (midwives and obstetricians) and pretested on a small sample of 10 pregnant women. One item proved to be unclear to the respondents ("I have fear I will not be able to help during the delivery"). Two additional items ("I have nightmares about the delivery" and "I have difficulty relaxing when thinking of the coming birth") were deleted on the request of the care providers. They worried that the items were scary, hence that by filing in the questionnaire women would become more anxious about the upcoming birth. The 13 preserved items are presented in Table 1. Respondents were asked to rate their level of anxiety for each of the 13 items on a 4-point Likert scale ( 1 = no anxiety; 2 = low anxiety; $3=$ moderate anxiety; $4=$ high anxiety). The instrument had a Cronbach's alpha of 0.81 , and its averaged total scores were significantly correlated $(r=0.55 ; p<0.001)$ with the averaged total scores of the antenatal version of W-DEQ developed by Wijma et al. (1998).

[Insert Table 1 about here.]

The type of antenatal care provider entered the analysis as a dichotomous variable with midwife (coded 1) or physician (coded 2) as categories. As stated earlier, respondents were invited to the study by either their midwife or obstetrician at 30 weeks of pregnancy. Hence, we assumed that the care provider who invited them to the study was their main antenatal care provider. 
Data Analysis. An analysis of differences in fear of childbirth between Belgium and the Netherlands presupposed that this concept was measured in an invariant way (Moors, 2004; van de Vijver, 2003). Measurement invariance refers to "whether or not, under different conditions of observing and studying phenomena, measurement operations yield measures of the same attribute" (Horn \& Mcardle, 1992 p. 117). If measurement invariance is absent, comparisons between countries become highly problematic, because observed between-group differences might be due to measurement artifacts caused by the differential cultural response patterns, rather than to real differences in the prevalence of childbirth fear (Vandenberg \& Lance, 2000). Thus, we paid attention to the cross-cultural equivalence of the measurement of fear of childbirth before coming to the cross-national comparison of effect variables and means.

Measurement invariance was tested via multi-group confirmatory factor analysis. It offered a very strong analytic framework for evaluating the invariance of measurement models across distinct groups and is currently considered the methodology of choice for assessing cross-national measurement invariance (Steenkamp \& Baumgartner, 1998). In the current study, we examined both effect parameters and means. This implies that metric equivalence or equivalence of the factor loadings between items and the dimensions we explored was needed. Additionally scalar invariance, or invariance of the corresponding item intercepts was required.

The different levels of measurement invariance were examined using maximum likelihood estimations. Analysis was conducted using the AMOS 17.0 program. We evaluated the acceptability of our model on the basis of three goodness of fit indices. The standard way to compare the overall fit of the different models is the chi-square test. However, this test may result in a type I error (and thus an incorrect rejection of the model) in cases of non-normality of data, complex models, and large sample sizes. Because the first two conditions were inherent to our study, we also report two model fit indices that have shown a more robust performance (Hu \& Bentler, 1998): the Comparative Fit Index, or CFI, (Bentler, 1990) and the Root Mean Squared Error of Approximation, or RMSEA, (Steiger, 1990). The first index ranges from 0 (poor fit) to 1 (perfect fit). A value of 0.90 or higher 
provides evidence for a good fit (Hu et al., 1998). The RMSEA indicates a good fit when its score is 0.08 or less (Browne \& Cudeck, 1992).

In a second step, we compared the observed average fear of childbirth for Belgian and Dutch women on the one hand, and for women in primary versus secondary care, on the other. $T$-tests were used as test statistics.

Finally, multivariable models were estimated using multiple regression analysis . Some sociodemographic variables (age, parity, and level of education) were controlled in the regression analysis as they can confound the association between antenatal care giver and fear of childbirth. Multiparae and older women are on average less fearful (Gurung, Dunkel-Schetter, Collins, Rini, \& Hobel, 2005; Geissbuehler \& Eberhard, 2002), but at the same time they are more likely to have an obstetric history which automatically sends them to secondary care. In Belgium, women planning a home birth, hence seeing a midwife instead of an obstetrician, are likely to have completed higher education (Gilleir, 2007; Christiaens \& Bracke, 2009). Age was a continuous variable, parity ( primiparae $=0 ;$ multiparae $=1)$ and level of education $($ no higher education $=0$; higher education $=$ 1) were dichotomized.

Analyses were performed using the mixed model procedure of SPSS 15.0 for each dimension of fear of childbirth, using restricted maximum likelihood estimation (Peugh \& Enders, 2005). Two models were estimated. The first model contained the main effects of country, type of antenatal care providers, and the control variables parity, level of education, and age. In the second model the interaction term country*type of antenatal care provider was added.

\section{Results}

\section{Testing for Invariance}


To test both forms of measurement invariance, we evaluated the best fitting factor structure of the shortened Childbirth Attitudes Questionnaire (Lowe, 2000). We proposed a model that contains four dimensions, loading together onto a higher order variable "fear of childbirth." Based on previous research (Saisto et al., 2003; Wijma, Alehagen, \& Wijma, 2002; Searle, 1996), fear about the baby's well-being, fear of labor pain and injuries, personal control-related fear, and fear of medical interventions and hospital care (see Introduction) were distinguished. The factor analysis we performed confirmed this four-fold factor structure. The first latent variable "fear related to the baby" was formed by the items "fear that something is wrong with the baby" and "fear that the baby could get hurt." The second latent variable "general and personal control-related fear" grouped together fear related to loss of self-control, and two general items: fear of delivery and general fear. The third latent variable "fear of pain and injuries" underlied fear of blood loss, fear of painful contractions, and fear of tearing. The last latent variable grouped together fear related to aspects of the hospital stay and medical interventions, such as fear about a caesarean section, fear of a painful injection, fear of being left alone, fear of receiving inappropriate care, and fear of the hospital environment. We additionally allowed for three pairs of items to correlate, because the meanings of these items were strongly related to one another. This was the case between fear of blood loss and painful contraction, between fear of tearing and caesarean section, and between fear of inappropriate care and hospital environment (Figure 1).

Our results indicated that the proposed four-factor model fitted well in both Belgium and the Netherlands, as well as in the pooled dataset. The model led to a significant chi-square, but the two other indices showed a good fit as indicated by CFI above 0.90 and by RMSEA below 0.08 (Table 2). Our results also allowed us to confirm metric and scalar invariance. Again a significant chi-square was found, but the CFI and RMSEA indices showed a good fit at both levels. This implied that the comparison of effect parameters as well as means between the Flemish and Dutch population were valid.

[Insert Figure 1 about here]

[Insert Table 2 about here.] 


\section{Cross-national Comparison}

The age of participating women ranged between 19 and 44 years, with a mean age of 31.2 years, 30.4 years for Belgian and 31.9 years for Dutch women. Multiparae made up $52.7 \%$ of all respondents, with $47.5 \%$ in Belgium and $57.1 \%$ in the Netherlands. More Belgian (76.9\%) than Dutch (40.5\%) women completed higher education (Table 3). Group comparisons of these variables showed significant country differences (education: $\mathrm{chi}^{2}=108.07 ; p<0.001 ;$ parity: chi $^{2}=7.668 ; p=0.006$; age: $t=-5.042 ; p<0.001$ ). Thus, parity, age, and educational level may have confounded the comparison between Belgium and the Netherlands. Therefore, we controlled for these variables in the multiple regression analyses.

[Insert Table 3 about here.]

The observed means (Table 4) revealed no significantly different levels of fear of childbirth between Belgian and Dutch women, except for the dimension of baby-related fear. Belgian women were a little more anxious about the condition of their baby than Dutch women $(p=0.047)$. However, the comparison by antenatal care providers showed significant differences in the average fear of childbirth. In every dimension except interventions and hospital-related fear, women in the care of a midwife were less fearful than women receiving care from an obstetrician.

[Insert Table 4 about here.]

In general, the absence of country effects was confirmed in multiple regression analyses (Table 5 and Figure 1). Belgian and Dutch women reported similar levels of baby-related, pain/injuryrelated, and general/personal-control related fear after controlling for confounding. However, intervention/hospital-related fear proved to be an exception. In fact, significantly more Belgian women receiving antenatal care from a midwife reported intervention/hospital-related fear 
compared to the other groups (Belgian women with physician, Dutch women with midwife, Dutch women with physician $)$ who reported similar levels of fear $\left(\mathrm{B}_{\text {country }}{ }_{\text {provider }}=0.27 ; p=0.005\right)$. However, although intervention/hospital-related fear was an important dimension, compared to the other dimensions, the estimated means were relatively low (Figure 2). Women especially reported babyand pain/injury-related fear.

In accordance with the medicalization hypothesis, antenatal care by midwives resulted in less fear (baby, general/personal control, and pain/injury), compared to care by obstetricians, both in Belgium and the Netherlands. In the parsimonious models the interaction term country*provider was not significant for the dimensions baby, general/personal control, and pain/injury (Table 5).

Multiparae and the higher educated women experienced less fear of childbirth, as was predicted by other authors (Gurung et al., 2005; Geissbuehler et al., 2002). Note that regarding intervention/hospital-related fear, parity was non-significant $(B=-0.069 ; p=0.157)$, which could indicate that the anti-medical reaction of Belgian women planning a home birth was unlikely to be the consequence of earlier negative birth experiences. Age was not significantly related to any dimension of fear of childbirth.

[Insert Table 5 about here.]

[Insert Figure 2 about here.]

DISCUSSION AND CONCLUSION

In this study, we compared Belgian and Dutch women's reports of fear of childbirth. In addition to country differences, we also investigated differences according to type of antenatal care provider. In addition, we paid attention to the cross-cultural equivalence of the measurement of fear of childbirth and applied a four-factor structure. This investigation resulted in three main findings. 
First, we found that a shortened Dutch version of the childbirth attitudes questionnaire developed by Lowe (2000) proved to be a functional equivalent for Belgium and the Netherlands, thus enabling a sound cross-national comparison of effect variables and means. The scale, measuring fear of childbirth, appeared to be a multi-dimensional construct consisting of four underlying subdimensions: fear about the well-being of the baby, fear of labor pain and injuries, general and personal control-related fear, and fear of medical interventions and the hospital environment. This approach integrates and summarizes insights from other authors (Searle, 1996; Saisto et al., 2003; Wijma et al., 2002) in one questionnaire. However, we do not argue that fear of childbirth is a multidimensional concept. Although it does seem rather likely from a theoretical point of view, other data (see recent studies: Nieminen et al., 2009; Lyberg \& Severinsson, 2010, Hall et al., 2009, Waldenström et al., 2006) and research techniques are needed to claim multi-dimensionality of the concept itself.

Second, like the cross-national study comparing Sweden and Denmark (Kjaerggard et al., 2008), our study found no significant country differences in fear of childbirth. However, fear about interventions and hospital care proved an exception. Significantly more Belgian women receiving antenatal care from a midwife reported intervention/hospital-related fear compared to the other groups (Belgian women with physician, Dutch women with midwife, and Dutch women with physician). Note that, compared to the other dimensions, the estimated means of intervention/hospital-related fear were relatively low. It would be interesting for future research to explore whether women have a hierarchy of fears. Do women give priority to the reduction of the most urgent fears over the less urgent? Are women willing to safeguard the well-being of the baby and to reduce labor pain at the expense of control loss and poor hospital care? Women especially reported baby- and pain/injury-related fear. One could theorize that to reduce baby- and pain/injuryrelated fear, women are prepared to set aside worries about personal control and birth environment. Belgian and Dutch women reported similar levels of pain/injury-related fear. This finding was in line with the earlier finding that Dutch and Belgian women giving birth in a hospital setting had a similar labor pain acceptance (Christiaens, Verhaeghe, \& Bracke, 2010), and hence contradicts the 
existence of a specific Dutch pain-culture. Dutch women showed a greater acceptance of labor pain compared to Americans in Senden's study (1988). Jordan (1978) concluded from a comparison between childbearing women in Yucatan, Sweden, the Netherlands, and the United States that the majority of Dutch women do not expect or get pain medication during labor. Also, DeVries (2004) mentions distinctive Dutch ideas about pain and discomfort, which are reflected in a low medical consumption. Despite diverging intervention and epidural rates in the Belgian and the Dutch models of maternity care, we found no differences in fear of labor.

Third, women receiving midwifery care experienced less fear compared to those in obstetric antenatal care; therefore, the medicalization hypothesis was confirmed. Although other recent studies (Fenwick et al., 2009, Hall et al., 2009) have reported similar results, it remains unclear whether causation or selection processes are at work. The first implies that the type of care giver is one of the determinants of fear of childbirth, while the latter means that more fearful women-or in the Dutch case, women referred to obstetric care on indication of fear of childbirth-may have chosen obstetric care instead of midwifery care to feel safer. To exclude selection, anxiousness before pregnancy should be controlled for. However, the gathering of pre-pregnancy data is methodologically quite challenging. Nevertheless, we agree with Hall et al. (2009) who suggested that the nature of the care received from the providers, more specifically the reassuring care by midwives could be the reason for the difference in childbirth fear. For what concerns the national contexts we were comparing, it might be that in the Netherlands, the higher fear scores in secondary care were related to complications arising during pregnancy, but in Belgium, $98 \%$ of pregnant women (hence, also the majority of low risk women) see an obstetrician throughout pregnancy. If complications were the reason for Dutch women in secondary care being more anxious about childbirth, we would have expected to find country differences. More specifically, among women cared for by an obstetrician the Dutch should then be more anxious than the Belgians, which was not the case. 
Attention should be drawn to some limitations of our investigation. First, a lack of information about non-response and the relatively low response rate may have concealed selection biases. For example, the Belgian sample had more higher-educated women than the Dutch sample. This may have indicated a selection bias, which may have affected the results. Zadoroznyj (1999) showed that women's orientation about control over their first birth is affected by their social class. More highly educated women are more likely to be informed about pregnancy and childbirth, which could have a reassuring, as well as a fear-inducing effect. Our analyses, however, were adjusted for level of education and confirmed the reassuring hypothesis, which is in line with the findings of Gurung et al. (2005) who found that the more highly educated women had more positive attitudes toward pregnancy.

Second, we attempted to quantify the differences in fear of childbirth between two similar countries, the Netherlands and the Dutch-speaking part of Belgium. This comparison may clarify the role of maternity care systems in fear of childbirth, as no other region resembles the Dutch society more closely than Belgium does. They have comparable geographical and demographical characteristics, share a common history, and have comparable political systems and welfare state regimes (Van Kersbergen, 1991). However, they differ with regard to the organization of health care in general and maternity care in particular. The variation in care practices equally means that uncontrolled confounding might be the case when comparing the two countries.

Third, we assumed that the care provider who invited participants to the study was the main antenatal care provider. Although this can be questioned, we assumed that at the moment of inclusion (at 30 weeks of pregnancy). most women decided on their main care provider. If errors occurred, obstetricians would have been falsely assumed to be the main care provider, because the majority of women receiving primary care both in Belgium and the Netherlands also consult an obstetrician for three ultrasounds throughout pregnancy.

Fourth, one of the underlying dimensions of the shortened version of the Childbirth Attitudes Questionnaire (baby-related fear) was based only on two items. This is generally considered as too few in the factor analysis literature, but at the same time this can be put in perspective by the 
importance of the conceptual framework that guides a confirmatory factor analysis (Brown, 2006). The baby-related fear subdimension is reasonable because the health and well-being of the baby is one of the major concerns of parents, health professionals and childbirth researchers. Moreover, it is also represented in other fear of childbirth scales, such as the Wijma Delivery Expectancy/Experience Questionnaire (W-DEQ) (Wijma, Wijma, \& Zar, 1998). In an exploratory factor analysis of the W-DEQ Johnson and Slade (2002) grouped the baby-related items together with other items, indicating the riskiness of birth. In addition the Cronbach's alpha for our two-item subdimension was 0.75 , the inter-item correlation was 0.60 , which indicates sufficient reliability and coherence of the babyrelated fear subdimension.

Fifth, we did not control for a potential social acceptability bias of self-report. However, our respondents were informed about the anonymity of the research and returned the questionnaires in closed envelopes to reduce socially desirable answers.

Despite these shortcomings, the present study is important. First, although fear of childbirth has been studied in several countries, such as Australia (Fenwick, Gamble, Nathan, Bayes, \& Hauck, 2009), Sweden (Areskog et al., 1981), Denmark (Laursen, Hedegaard, \& Johansen, 2008), and China (Tsui et al., 2006), it has not been the subject of cross-national comparisons, except for a study by Kjaerggard et al. (2008) who argued that Denmark and Sweden have a similar childbirth culture, but that they differ in the organization of midwifery care. Here we surveyed Belgian and Dutch women within the same study, set up with the explicit aim of cross-national comparison. Questionnaires were administered at the same moment in time (2004-2005) and followed the same sampling and data collection methods. Second, attention was paid to the cross-cultural equivalence of the measurement of fear of childbirth (Harkness, van de Vijver, \& Mohler, 2003; Steenkamp et al., 1998), an issue that is too often neglected.

In sum, based on our findings, it is clear that at the country level, few differences in fear of childbirth were found. In other words, in the Belgian maternity care system, which emphasizes secondary care, women were as fearful as those in the Dutch midwifery model of care. However, at the level of doctor-patient interaction, an adverse medicalization effect became visible. In previous 
research, similar results have been reported: women who gave birth under supervision of an obstetrician were less satisfied about childbirth compared to women with a midwife-led birth, both in Belgium and the Netherlands (Christiaens et al., 2009). Future research should explore the underlying mechanisms through which, at the interpersonal level, medical care seems to be less satisfactory and reassuring than midwifery care.

The results of our study imply that fear of childbirth does not so much originate from the characteristics of the maternity care system, but from the interpersonal contact between the pregnant women and the care provider. Especially obstetricians should be more attentive to the problem of fear of childbirth and try to anticipate in face-to-face encounters with their clients. In addition, women would benefit from obstetricians and midwives working more closely together. Midwife led antenatal care alternating with consulting an obstetrician might be a good model of care.

TABLE 1. Items of the Shortened Childbirth Attitudes Questionnaire

I have fear of losing control of myself at the delivery. I am really afraid of giving birth.

I have fear of bleeding too much during the delivery. I have fear of something being wrong with the baby. I have fear of painful injections.

I have fear of being left alone during labor.

I have fear of having to have a Caesarean section.

I have fear of being torn with the birth of the baby.

I have fear of the baby being injured during the delivery.

I have fear of painful labor contractions.

I have fear of the hospital environment.

I have fear of not getting the kind of care that I want.

Overall, I would rate my anxiety about childbirth as 1 (no anxiety), 2 (low anxiety), 3 (moderate anxiety), or 4 (high anxiety). 
TABLE 2. Model Fit Summary: Chi-square, CFI, RMSEA

\begin{tabular}{lcccc}
\hline & $\mathrm{Chi}^{2}$ & Df & CFI & RMSEA \\
\hline Fit factor model & & & & \\
\hline Pooled dataset & 300.302 & 58 & 0.921 & 0.072 \\
Belgium & 161.584 & 58 & 0.926 & 0.070 \\
Netherlands & 198.002 & 58 & 0.918 & 0.075 \\
\hline Measurement invariance tests & & & \\
\hline Configural & 359.585 & 116 & 0.922 & 0.051 \\
Metric & 381.142 & 128 & 0.919 & 0.050 \\
Scalar & 411.298 & 141 & 0.913 & 0.049 \\
\hline
\end{tabular}

TABLE 3. Descriptive Statistics in Total Sample and for Belgian and Dutch Women Separately

\begin{tabular}{lcccc}
\hline & & TOTAL & Belgium & THE NETHERLANDS \\
\hline Higher than & $\%$ & 57.1 & 76.9 & 40.5 \\
secondary & $\mathrm{n}$ & 458 & 281 & 177 \\
education & $\mathrm{Cl}$ & $0.55-0.59$ & $0.75-0.79$ & $0.38-0.43$ \\
& & & & \\
& & & & \\
Multiparae & $\%$ & 52.7 & 47.5 & 57.1 \\
& $\mathrm{n}$ & 434 & 178 & 258 \\
& $\mathrm{Cl}$ & $0.51-0.55$ & $0.44-0.50$ & $0.55-0.59$ \\
& & & & \\
Age (years) & $\mathrm{M}$ & 31.2 & 30.4 & 31.9 \\
& $\mathrm{SD}$ & 4.17 & 4.09 & 4.14 \\
& $\mathrm{n}$ & 816 & 372 & 444 \\
& $\mathrm{Cl}$ & $31.06-31.36$ & $30.20-30.62$ & $31.68-32.07$ \\
\hline
\end{tabular}


TABLE 4. Observed (Unadjusted) Means and $t$-test results

\begin{tabular}{|c|c|c|c|c|c|c|}
\hline Fear & Country & Mean $^{1}$ & SD & $\mathrm{N}$ & $\mathrm{t}$ & $P$ \\
\hline \multirow{2}{*}{ Baby-related } & Belgium & 1.65 & 0.88 & 376 & \multirow{2}{*}{1.99} & \multirow{2}{*}{0.047} \\
\hline & the Netherlands & 1.53 & 0.85 & 449 & & \\
\hline \multirow{2}{*}{$\begin{array}{l}\text { General/personal } \\
\text { control -related }\end{array}$} & Belgium & 1.23 & 0.73 & 376 & \multirow{2}{*}{0.57} & \multirow{2}{*}{0.569} \\
\hline & the Netherlands & 1.20 & 0.75 & 449 & & \\
\hline \multirow{2}{*}{ Pain/injury-related } & Belgium & 1.40 & 0.70 & 376 & \multirow{2}{*}{-1.155} & \multirow{2}{*}{0.249} \\
\hline & the Netherlands & 1.46 & 0.75 & 449 & & \\
\hline \multirow{2}{*}{$\begin{array}{l}\text { Intervention/hospital- } \\
\text { related }\end{array}$} & Belgium & 0.93 & 0.66 & 376 & \multirow{2}{*}{0.629} & \multirow{2}{*}{0.530} \\
\hline & the Netherlands & 0.90 & 0.67 & 449 & & \\
\hline Fear & $\begin{array}{l}\text { Antenatal care } \\
\text { provider }\end{array}$ & Mean $^{1}$ & SD & $\mathrm{N}$ & $\mathrm{t}$ & $P$ \\
\hline \multirow{2}{*}{ Baby-related } & Midwife & 1.40 & 0.81 & 381 & \multirow{2}{*}{-5.81} & \multirow{2}{*}{$<0.001$} \\
\hline & Physician & 1.75 & .089 & 444 & & \\
\hline \multirow{2}{*}{$\begin{array}{l}\text { General/personal } \\
\text { control -related }\end{array}$} & Midwife & 1.08 & 0.71 & 381 & \multirow{2}{*}{-4.77} & \multirow{2}{*}{$<0.001$} \\
\hline & Physician & 1.33 & 0.75 & 444 & & \\
\hline \multirow{2}{*}{ Pain/injury-related } & Midwife & 1.38 & 0.72 & 381 & \multirow{2}{*}{-2.14} & \multirow{2}{*}{0.033} \\
\hline & Physician & 1.49 & 0.73 & 444 & & \\
\hline \multirow{2}{*}{$\begin{array}{l}\text { Intervention/hospital- } \\
\text { related }\end{array}$} & Midwife & 1.00 & 0.70 & 381 & \multirow{2}{*}{3.53} & \multirow{2}{*}{$<0.001$} \\
\hline & Physician & 0.84 & 0.62 & 444 & & \\
\hline
\end{tabular}

${ }^{1}: \min .=0 ; \max .=4$ 
TABLE 5. Multiple Regression Models for Each Dimension of Fear of Childbirth

\begin{tabular}{|c|c|c|c|c|c|}
\hline \multicolumn{6}{|l|}{ BABY } \\
\hline & \multirow{2}{*}{ B } & \multirow{2}{*}{ S.E. } & \multirow{2}{*}{$p$} & \multicolumn{2}{|c|}{$95 \%$ C.I. for B } \\
\hline & & & & Upper & Lower \\
\hline Intercept & 1.199 & 0.242 & 0.000 & 0.724 & 1.674 \\
\hline Multiparous (= 1) & -0.132 & 0.063 & 0.038 & -0.256 & -0.007 \\
\hline Age & 0.003 & 0.008 & 0.695 & -0.012 & 0.019 \\
\hline Higher educated $(=1)$ & -0.123 & 0.067 & 0.067 & -0.253 & 0.008 \\
\hline The Netherlands (= 1 ) & -0.086 & 0.068 & 0.204 & -0.220 & 0.047 \\
\hline Obstetrician (= 1) & 0.309 & 0.061 & 0.000 & 0.188 & 0.429 \\
\hline \multicolumn{6}{|c|}{ GENERAL/PERSONAL CONTROL } \\
\hline & \multirow{2}{*}{ B } & \multirow{2}{*}{ S.E. } & \multirow{2}{*}{$p$} & \multicolumn{2}{|c|}{ 95\% C.I. for B } \\
\hline & & & & Upper & Lower \\
\hline Intercept & 0.813 & 0.206 & 0.000 & 0.409 & 1.218 \\
\hline Multiparous (= 1) & -0.220 & 0.054 & 0.000 & 0.326 & -0.114 \\
\hline Age & 0.009 & 0.007 & 0.195 & -0.004 & 0.022 \\
\hline Higher educated $(=1)$ & -0.164 & 0.057 & 0.004 & -0.276 & 0.053 \\
\hline The Netherlands ( $=1$ ) & -0.036 & 0.058 & 0.528 & -0.150 & 0.077 \\
\hline Obstetrician (= 1) & 0.228 & 0.052 & 0.000 & 0.125 & 0.330 \\
\hline \multicolumn{6}{|l|}{ PAIN/INJURY } \\
\hline & \multirow{2}{*}{ B } & \multirow{2}{*}{ S.E. } & \multirow{2}{*}{$p$} & \multicolumn{2}{|c|}{ 95\% C.I. for B } \\
\hline & & & & Upper & Lower \\
\hline Intercept & 1.492 & 0.204 & 0.000 & 1.091 & 1.892 \\
\hline Multiparous (= 1) & -0.238 & 0.053 & 0.000 & -0.343 & -0.133 \\
\hline Age & -0.003 & 0.007 & 0.681 & -0.016 & 0.010 \\
\hline Higher educated $(=1)$ & -0.099 & 0.056 & 0.078 & -0.210 & 0.011 \\
\hline The Netherlands (= 1 ) & 0.072 & 0.057 & 0.207 & -0.040 & 0.185 \\
\hline Obstetrician $(=1)$ & 0.109 & 0.052 & 0.036 & 0.007 & 0.210 \\
\hline \multicolumn{6}{|l|}{ INTERVENTION/HOSPITAL } \\
\hline & \multirow{2}{*}{ B } & \multirow{2}{*}{ S.E. } & \multirow{2}{*}{$p$} & \multicolumn{2}{|c|}{ 95\% C.I. for B } \\
\hline & & & & Upper & Lower \\
\hline Intercept & 1.761 & 0.211 & 0.000 & 1.347 & 2.176 \\
\hline Multiparous (= 1) & -0.069 & 0.049 & 0.157 & -0.164 & 0.026 \\
\hline Age & -0.005 & 0.006 & 0.450 & -0.016 & 0.007 \\
\hline Higher educated $(=1)$ & -0.156 & 0.051 & 0.002 & -0.257 & -0.056 \\
\hline The Netherlands (= 1 ) & -0.508 & 0.156 & 0.001 & -0.814 & -0.203 \\
\hline Obstetrician (= 1) & -0.339 & 0.071 & 0.000 & -0.477 & -0.200 \\
\hline Netherlands*obstetrician & 0.265 & 0.095 & 0.005 & 0.080 & 0.451 \\
\hline
\end{tabular}


Figure 1. Factor structure of the shortened Childbirth Attitudes Questionnaire

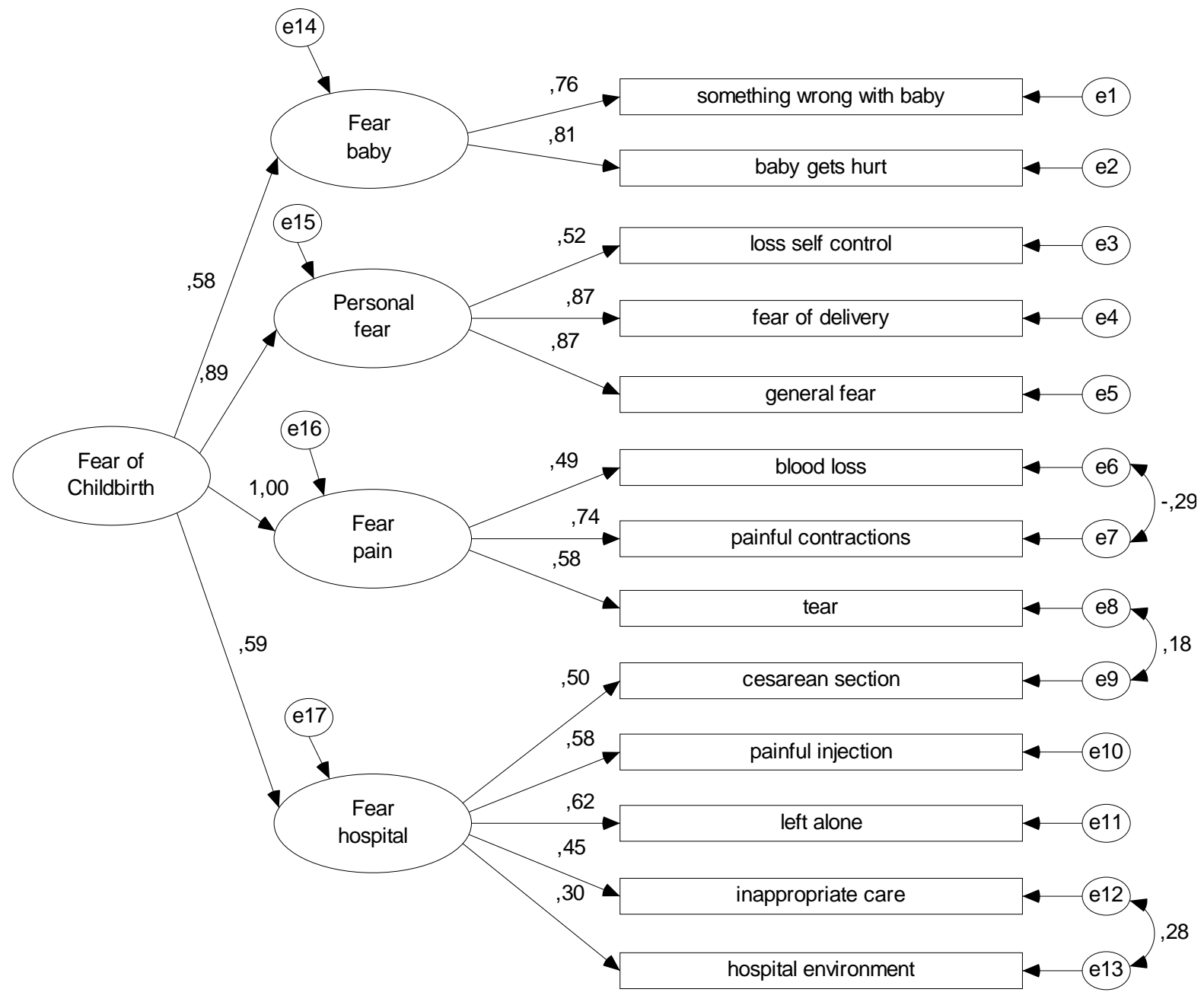


FIGURE 2. Estimated Means for Each Dimension of Fear of Childbirth

\section{Baby-related fear}

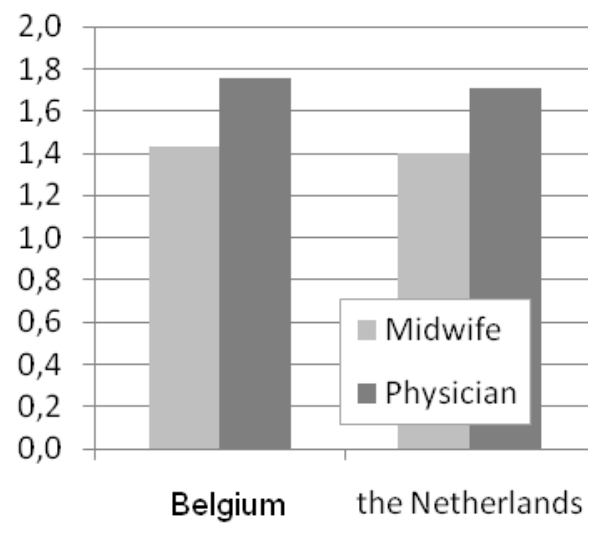

\section{Pain/injury-related fear}

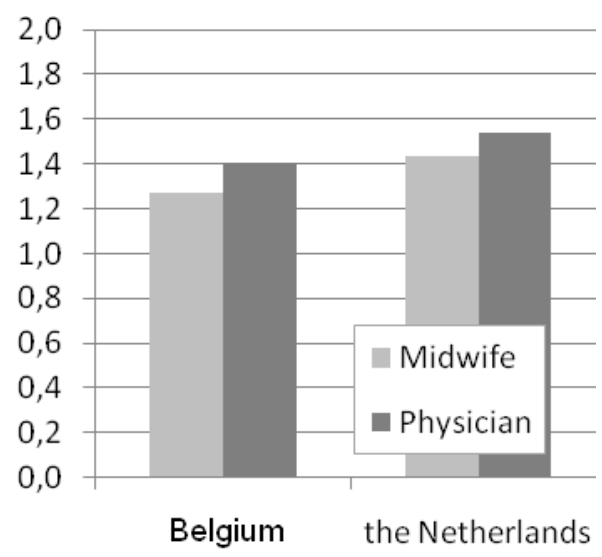

General/personal control-related fear

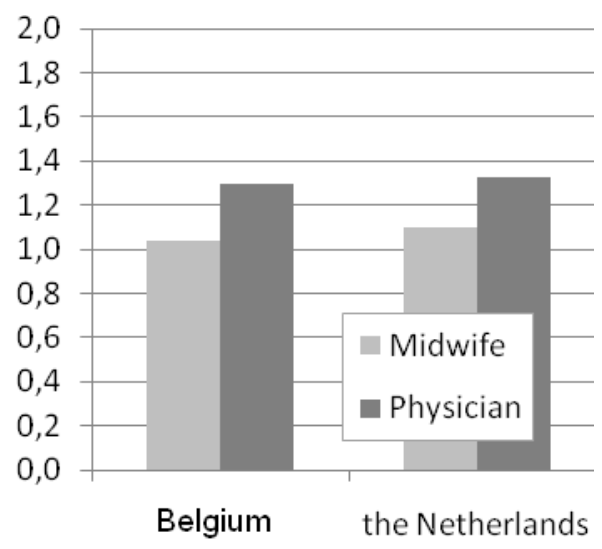

\section{Interventions-hospital-related fear}

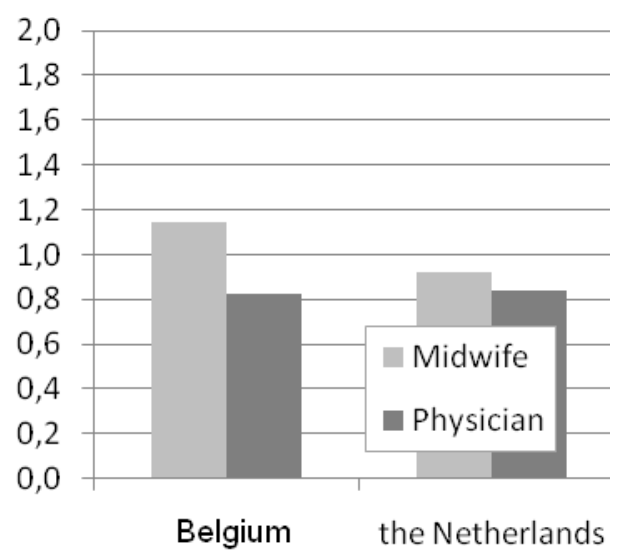

Reference List

Areskog, B., Uddenberg, N., \& Kjessler, B. (1981). Fear of Childbirth in Late Pregnancy. Gynecologic and Obstetric Investigation, 12, 262-266.

Arrindell, W. A. \& Ettema, J. H. M. (1986). SCL-90: handleiding bij een multidimensionele psychopathologie-indicator. Lisse: Swets, Test Publishers. 
Ayers, S. \& Pickering, A. D. (2005). Women's expectations and experience of birth.

Psychology \& Health, 20, 79-92.

Bentler, P. M. (1990). Comparative Fit Indexes in Structural Models. Psychological Bulletin, $107,238-246$

Brown, T. A. (2006). Confirmatory factor analysis for applied research. New York: Guilford Press.

Browne, M. W. \& Cudeck, R. (1992). Alternative Ways of Assessing Model Fit. Sociological Methods \& Research, 21, 230-258.

Christiaens, W. \& Bracke, P. (2009). Place of birth and satisfaction with childbirth in Belgium and the Netherlands. Midwifery, 25, e11-e19.

Christiaens, W., Gouwy, A., \& Bracke, P. (2007). Does a referral from home to hospital affect satisfaction with childbirth? A cross-national comparison. BMC Health Services Research, 7.

Christiaens, W., Verhaeghe, M., \& Bracke, P. (2010). Pain acceptance and personal control in pain relief in two maternity care models: a cross-national comparison of Belgium and the Netherlands. Bmc Health Services Research, 10.

Cochran, W. G. (1977) Sampling techniques. New York: John Wiley and Sons.

Davis-Floyd, R. (2001). The technocratic, humanistic, and holistic paradigms of childbirth. International Journal of Gynecology \& Obstetrics, 75, S5-S23.

Davis-Floyd, R. E. (1994). The Technocratic Body - American Childbirth As Cultural Expression. Social Science \& Medicine, 38, 1125-1140. 
De Vries, R. (2004). A Pleasing birth. Midwives and maternity care in the Netherlands. Philadelphia: Temple University Press.

Derogatis, L. R. (1977). The SCL-90 Manual I: Scoring, administration and procedures for the SCL-90 Baltimore: Johns Hopkins University School of Medicine, Clinical Psychometrics Unit.

Derogatis, L. R. \& Cleary, P. A. (1977). Confirmation of Dimensional Structure of Scl-90 - Study in Construct-Validation. Journal of Clinical Psychology, 33, 981-989.

Eriksson, C., Westman, G., \& Hamberg, K. (2005). Experiential factors associated with childbirth-related fear in Swedish women and men: A population based study. Journal of Psychosomatic Obstetrics and Gynecology, 26, 63-72.

Fenwick, J., Gamble, J., Nathan, E., Bayes, S., \& Hauck, Y. (2009). Pre- and postpartum levels of childbirth fear and the relationship to birth outcomes in a cohort of Australian women. Journal of Clinical nursing, 18, 667-677.

Fenwick, J., Hauck, Y., Downie, J., \& Butt, J. (2005). The childbirth expectations of a selfselected cohort of Western Australian women. Midwifery, 21, 23-35.

Fisher, C., Hauck, Y., Fenwick, J., (2006). How social context impacts on women's fears of childbirth: A Western Australian example. Social Science \& Medicine, 63, 64-75.

Geissbuehler, V. \& Eberhard, J. (2002). Fear of childbirth during pregnancy: a study of more than 8000 pregnant women. Journal of Psychosomatic Obstetrics and Gynecology, 23, 229-235.

Gilleir, C. (2007). Thuis bevallen in Vlaanderen: een kwestie van reflexiviteit (Home birth in Flanders: a matter of reflexivity). Tijdschrift voor Sociologie, 28, 25-51.

Gurung, R. A. R., Dunkel-Schetter, C., Collins, N., Rini, C., \& Hobel, C. J. (2005). Psychosocial predictors of prenatal anxiety. Journal of Social and Clinical Psychology, 24, 497-519. 
Hall, W. A., Hauck, Y. L., Carty, E. M., Hutton, E. K., Fenwick, J., Stoll, K. (2009). Childbirth fear, anxiety, fatigue, and sleep deprivation in pregnant women. JOGNN - Journal of Obstetric Gynecologic and Neonatal Nursing, 38, 567-576.

Harkness, J. A., van de Vijver, F. J. R., \& Mohler, P. (2003). Cross-cultural survey methods. New York: John Wiley.

Hildingsson, I., Waldenstrom, U., \& Radestad, I. (2002). Women's expectations on antenatal care as assessed in early pregnancy: number of visits, continuity of caregiver and general content. Acta Obstetricia et Gynecologica Scandinavica, 81, 118-125.

Horn, J. L. \& Mcardle, J. J. (1992). A Practical and Theoretical Guide to Measurement Invariance in Aging Research. Experimental Aging Research, 18, 117-144.

Hu, L. T. \& Bentler, P. M. (1998). Fit indices in covariance structure modeling: Sensitivity to underparameterized model misspecification. Psychological Methods, 3, 424-453.

Illich, I. (1976). Limits to medicine. Medical Nemesis: the expropriation of health. London: Marion Boyars.

Johanson, R., Newburn, M., \& Macfarlane, A. (2002). Has the medicalisation of childbirth gone too far? British Medical Journal, 324, 892-895.

Johnson, T. R., Callister, L. C., Freeborn, D. S., Beckstrand, R. L., \& Huender, K. (2007). Dutch women's perceptions of childbirth in the Netherlands. Mcn-the American Journal of Maternal-Child Nursing, 32, 170-177.

Johnson, R. \& Slade, P. (2002) Does fear of childbirth during pregnancy predict emergency caesarean section? BJOG-An international Journal of Obstetrics and Gynaecology, 109, 1213-1221. 
Jordan, B. (1978). Birth in four cultures: a crosscultural investigation of childbirt in Yucatan,

Holland, Sweden, and the United States. Montreal: Eden Press Women's Publications, Inc.

Kjaerggard, H., Wijma, K., Dykes, A. K., \& Alehagen, S. (2008). Fear of childbirth in obstetrically low-risk nulliparous women in Sweden and Denmark. Journal of Reproductive and Infant Psychology, 26, 340-350.

Laursen, M., Hedegaard, M., \& Johansen, C. (2008). Fear of childbirth: predictors and temporal changes among nulliparous women in the Danish National Birth Cohort. Bjog-An International Journal of Obstetrics and Gynaecology, 115, 354-360.

Lowe, N. K. (2000). Self-efficacy for labor and childbirth fears in nulliparous pregnant women. Journal of Psychosomatic Obstetrics and Gynecology, 21, 219-224.

Lyberg, A. \& Severinsson, E. (2010). Fear of childbirth: mothers' experiences of teammidwifery care - a follow-up study. Journal of Nursing Management, 18, 383-390.

Moors, G. (2004). Facts and artefacts in the comparison of attitudes among ethnic minorities. A multigroup latent class structure model with adjustment for response style behavior. European Sociological Review, 20, 303-320.

Nieminen, K., Stephansson, O., \& Ryding, E. L., (2009). Women's fear of childbirth and preference for cesarean section - cross-sectional study at various stages of pregnancy in Sweden. Acta Obstetricia et Gynecologica, 88, 807-813

Peugh, J. L. \& Enders, C. K. (2005). Using the SPSS mixed procedure to fit cross-sectional and longitudinal multilevel models. Educational and Psychological Measurement, 65, 811-835.

Saisto, T. \& Halmesmaki, E. (2003). Fear of childbirth: a neglected dilemma. Acta Obstetricia et Gynecologica Scandinavica, 82, 201-208. 
Saisto, T. \& Halmesmaki, E. (2007). Fear of childbirth can be treated, and cesarean section on maternal request avoided. Acta Obstetricia et Gynecologica Scandinavica, 86, 1148-1149.

Searle, J. (1996). Fearing the worst - Why do pregnant women feel 'at risk'? Australian \& New Zealand Journal of Obstetrics \& Gynaecology, 36, 279-286.

Senden, I. P. M., Vanderwetering, M. D., Eskes, T. K. A. B., Bierkens, P. B., Laube, D. W., \& Pitkin, R. M. (1988). Labor Pain - A Comparison of Parturients in A Dutch and An American Teaching Hospital. Obstetrics and Gynecology, 71, 541-544.

Sjogren, B. (2000). Childbirth: expectations, choices, and trends. Lancet, 356, S12.

Steenkamp, J. B. E. M. \& Baumgartner, H. (1998). Assessing measurement invariance in crossnational consumer research. Journal of Consumer Research, 25, 78-90.

Steiger, J. H. (1990). Structural Model Evaluation and Modification - An Interval Estimation Approach. Multivariate Behavioral Research, 25, 173-180.

Stichting Perinatale Registratie Nederland (SPRN) (2007). Perinatale zorg in Nederland 2007 Bilthoven: SPRN.

Studiecentrum voor Perinatale Epidemiologie (SPE) (2005) Jaarrapport perinatale activiteiten in Vlaanderen 2005. Brussel: SPE.

Tsui, M. H., Pang, M. W., Melendey, H. L., Xu, L., Lau, T. K., \& Leung, T. N. (2006). Maternal fear associated with pregnancy and childbirth in Hong Kong Chinese women. Women \& Health, 44, 79-92.

van de Vijver, F. J. R. (2003). Cross-cultural survey methods. In J.Harkness, F. J. R. Van de Vijfer, \& P. Mohler (Eds.), Bias and equivalence (pp. 143-155). New Jersey: Wiley \& Sons. 
Van der Hulst, L. A. M., van Teijlingen, E., Bonsel, G. J., Eskes, M., Birnie, E., \& Bleker, O. Dutch women's decision-making in preganancy and labour as seen through the eyes of their midwives. Midwifery, (in press).

Van Kersbergen K (1991). Social Capitalism: A study of Christian democracy and the post-war settlement of the welfare state (Rep. No. Doctoral dissertation). Europan University Institute.

van Teijlingen, E. (2005). A critical analysis of the medical model as used in the study of pregnancy and childbirth. Sociological Research Online, 10, http://www.socresonline.org.uk/102/teijlingen.html.

Vandenberg, R. J. \& Lance, C. E. (2000). A review and synthesis of the measurement invariance literature: suggestions, practices, and recommendations for organizational research. Organisation Research Methods, 2, 4-69.

Waldenström, U., Hildingsson, I., \& Ryding, E. L. (2006) Antenatal fear of childbirth and its association with subsequent caesarean section and experience of childbirth. BJOG - An international Journal of Obstatrics and Gynaecology, 113, 638-646.

Watson, J. P., Elliot, S. A., Rugg, A. J., \& Brough D. I. (1984). Psychiatric disorder in pregnancy and the first postnatal year. British Journal of Psychiatry, 144, 453-462.

Wiegers, T. A., van der Zee, J., \& Keirse, M. J. N. C. (1998). Transfer from home to hospital: what is its effect on the experience of childbirth? Birth-Issues in Perinatal Care, 25, 19-24.

Wijma, K. (2003). Why focus on 'fear of childbirth'. Journal of Psychosomatic Obstetrics and Gynecology, 24, 141-143.

Wijma, K., Alehagen, S., \& Wijma, B. (2002). Development of the delivery fear scale. Journal of Psychosomatic Obstetrics and Gynecology, 23, 97-107. 
Wijma, K., Wijma, B., \& Zar, M. (1998). Psychometric aspects of the W-DEQ: a new questionnaire for the measurement of fear of childbirth. Journal of Psychosomatic Obstetrics and Gynecology, 19, 84-97.

Zadoroznyj M. (1999). Social class, social selves and social control in childbirth. Sociology of health and illness 21[3], 267-289.

Ref Type: Generic

Zar, M., Wijma, K., \& Wijma, B. (2001). Pre and postpartum fear of childbirth in nulliparous and parous women. Scandinavian Journal of Behaviour Therapy, 30, 75-81.

Zola, I. K. (1972). Medicine as an institution of social control. Sociological Review, 20, 487504. 